\title{
Modelling Noise Exposure by Means of Infrared Technology
}

\author{
Gabriel Fedorko ${ }^{1 *}$, Dávid Heinz'1 Vieroslav Molnár², Tomáš Brenner ${ }^{1}$ \\ 1 Technical University of Košice, Faculty of Mining, Ecology, Process Control and Geotechnology Letná 9, \\ 04200 Košice, Slovak Republic \\ 2 Technical University of Košice, Faculty of Manufacturing Technologies with a seat in Prešov, Bayerova 1, \\ 08001 Prešov, Slovak Republic \\ * Corresponding author's e-mail: gabriel.fedorko@tuke.sk
}

\begin{abstract}
Noise measurement for the design of anti-noise measures is used as a tool to identify and evaluate the existing noise situation. The measurements are carried out in the vicinity of selected roads to demonstrate the need for the design of anti-noise measures or to assess the effectiveness of the measures. Where the measurements are performed for the design, detection and assessment of the effectiveness of a noise protection measure in relation to the protection of public health, such measurements shall be carried out by a person holding a Certificate of Professional Qualification for Qualitative and Quantitative Verification of Environmental Factors to assess their potential impact on health - noise measurement. The paper presents the modelling of the noise exposure using the infrared technology in the given area and the simulation of measures on the main road routes of the model.
\end{abstract}

Keywords: noise exposure, simulation, infrared technology

\section{INTRODUCTION}

The impact of noise on the population has increasing consequences related to the development of civilization. Almost every activity a person performs makes noise. In the past, very little attention has been paid to dealing with noise pollution in the vicinity of residential buildings. This was mainly due to the low degree of automobilization at the time of construction of large housing clusters. Traffic noise is one of the greatest problems of large cities and agglomerations.

In the past, there was no substantial dynamism expected in the development of road transport in any of the cities, and therefore the requirements for the construction of transport infrastructure were not adapted in that way. In the context of infrastructure neglect, other problems began to arise, such as the safety of road traffic users on the highly exposed roads, a significant reduction in the housing comfort and the related cost of building alterations to people's homes.
In view of the problems posed by transport, attention will be focused on road traffic noise and, in particular, its prevention in the construction process by designing effective anti-noise measures and the organization of transport using professional prediction software [1]. Due to the great variability of the sound levels in a city, the static characteristics based on average values are out of favour.

The distribution of the difference analysis between the measured and the calculated sound level is carried out in order to evaluate the accuracy of the noise model and to analyze the different urban and road traffic characteristics that affect their uncertainties [2]. Today, noise pollution is a serious threat to the people living in cities. Mapping the urban noise using the NoiseSense system may be useful to mitigate the negative impact of noise [3].

It is well-known that the quality of the acoustic environment is very often degraded by large environmental interventions such as highways. 
In view of this, the European Union has imposed on its Member States the relevant legislation to monitor these environmental changes / interventions as well as to develop strategic noise maps and action plans to protect the natural and human environment [4]. The phenomenon of urbanization and the related transport networks in cities means preventing the increase in the population exposed to environmental pollution.

Regarding the exposure to noise, the Environmental Noise Directive requires a major metropolis to produce noise maps [5]. The noise pollution from the construction activities is a significant factor endangering the occupational health and the environment. However, the research has focused more on reducing the noise pollution of the surrounding sensitive off-site buildings rather than of the on-site workers. In addition, the currently available noise reduction methods tend to be passive and accompanied by significant additional costs [6].

At present, the noise effect can be considered one of the most serious problems under the modern urban conditions. Traffic noise is one of the main sources of noise in the urban environment. Formalization and modelling of traffic flows should be carried out using impact diagrams. The provision of the Sound-City-Tests program has been developed for the calculation of external noise sources and for the development of dynamic maps using the principles of object-oriented visual programming [7].

Today, more than half of the world's population lives in urban areas. As this share is expected to continue to grow, sustainable urban development is of utmost importance for guaranteeing the quality of life of the people living there. The environmental noise is one of the main problems to be addressed given its negative impact on the human health. In recent decades, various national and international noise directives and legislation have been defined to be observed by the local authorities in relation to noise mapping [8].

Noise, commonly defined as unwanted sound, is an environmental problem to which people are exposed throughout their lives. The important sources of noise and vibration are represented by the transport equipment involved in road, rail and air transport. Their noise and vibration are extremely harmful to the passengers and drivers as well as to the environment [9]. Intentionally varying the terrain ripples and terrain characteristics (acoustic landscaping) are regarded as a potential solution to reduce road noise.

However, there is hardly any research into the validity of sound propagation models to predict their effectiveness. Long-term continuous measurements of the sound pressure level and sound propagation were carried out near places with complex road traffic [10]. Virtual 3D city models are being increasingly used to model the realworld areas for use in many environmental simulation applications, including urban planning, energy mapping of the buildings, noise mapping, flood modelling and the like [11].

\section{THE IMPACT OF NOISE ON THE POPULATION}

The basic definition states that noise is any unwanted, disturbing, annoying or harmful sound. The prolonged exposure to noise can permanently damage the hearing organ. The common idea of noise is that it can only affect our hearing and that only the people working in a noisy sector such as construction or metallurgy are at risk. Noise causes many health problems, beginning with headaches, ending with hearing loss and in extreme cases death. Scientists have proven that noise does not even have to be perceived and can still cause problems. Perception of noise is a subjective question of a particular individual and therefore its effect is different for each person.

\section{CURRENT SOLUTIONS FOR NOISE SITUATION IN CONNECTION WITH ROAD TRAFFIC NOISE}

Possible solutions to excessive noise can be divided into:

Landscape planning:

- at this stage the emphasis is placed on the efficiency of the overall social perspective

- this phase can be considered as crucial.

Comprehensive technical:

- grade-separated intersections - increase the flow of road traffic and thus reduce the generation of noise and emissions at the point where vehicles would have to stop

- noise barriers - due to the high degree of urbanization they are the most common tool for combating noise 


\section{Comparison of Levels of Noise (dB)}

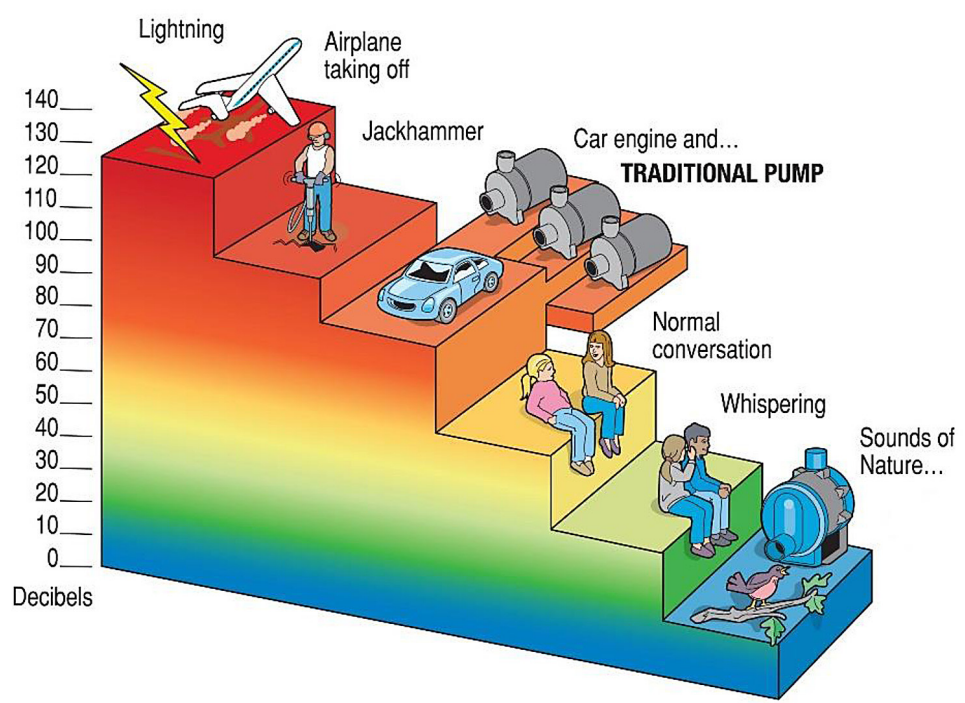

Fig. 1. Indicative noise values [12]

- road surface treatment - under certain circumstances, the road surface affects the intensity of the traffic noise. In this case, it seems to be more of an economic problem, given the prices of quality road surfaces.

Organizational:

- green wave at traffic lights - it can only be considered as a temporary solution, because on less exposed roads, vehicles must still stop at the intersection

- speed reduction - may have an impact on noise reduction, but the flow of traffic will be longer and, therefore, this measure can also be considered temporary.

Legislative:

- laws - within the Slovak Republic, environmental noise is dealt with by Act No. 2/2005 Coll., on assessment and control of environmental noise and Act no. 355/2007 Coll., on the protection, promotion and development of public health

- decrees - Decree No. 549/2007 Coll., laying down details of permissible values of noise, infrasound and vibration and requirements for the objectification of noise, infrasound and vibration in the environment

- standards - STN ISO 1996-1 Acoustics. Description, measurement and assessment of environmental noise. Part 1: Basic quantities and assessment procedures and STN ISO 1996-2 Acoustics. Description, measurement and assessment of environmental noise. Part 2: Determination of noise levels
- EC and EP Regulations - Directive 2002/49 EC of the European Parliament and of the Council on the Assessment and Control of Environmental Noise.

Sanitary:

- determination of limit values - permissible values are set by Decree no. 549/2007 Coll.

- noise prediction - noise prediction can significantly prevent the negative impacts from road transport already at the planning stage

- noise control measurements - are an effective control tool but can only be checked the state as it is

- noise maps - in the long term, they seem to be a good tool for land-use planning, but at present only Bratislava and Košice are obliged to produce a noise map in Slovakia

\section{MODELLING METHODOLOGY}

The mathematical model of road traffic noise prediction was processed by the Lima prediction software. The Lima prediction software is one of the most accurate softwares in its field. With its design, environment and partly also with its control, this software is similar to the CAD software.

For the design and visualization of the noise control measures, a representative area has been modelled which by its appearance, function, as well as population size, reflects a real part of the 


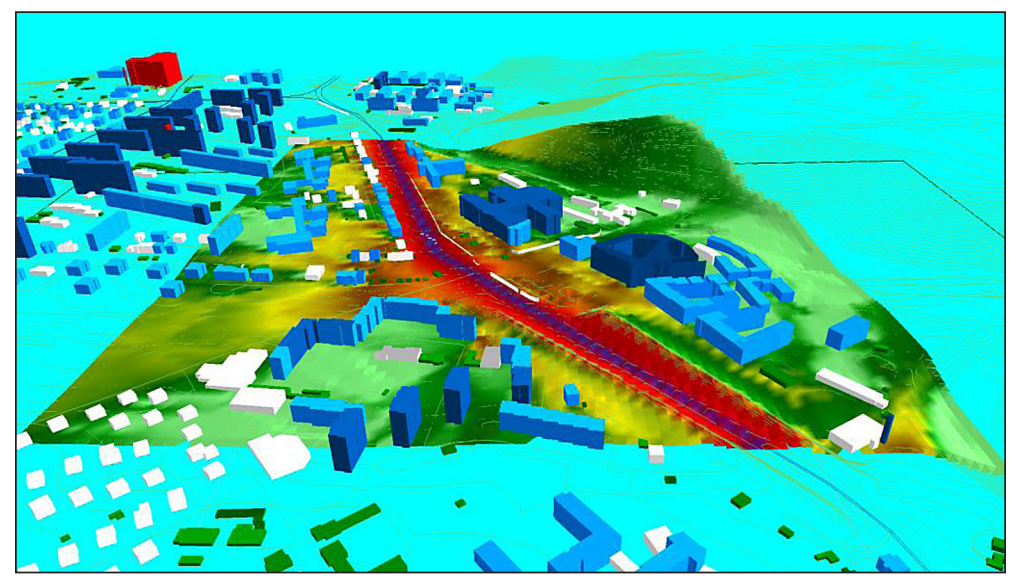

Fig. 2. Noise map example [1]

village or town. The modelled area includes residential blocks of flats, apartment houses and family houses (hereinafter referred to as buildings). The heights of the buildings are derived from the number of the above-ground floors of individual buildings determined by the survey of representative samples of residential buildings. The objects in the model are embedded in real terrain represented by contour lines of $1 \mathrm{~m}$ step. The absorption of terrain was taken into account in the model.

On roads and hard surfaces (compacted terrain, concrete, etc.), the surface coefficient was $\mathrm{G}=0.1$. On grass surfaces, the surface coefficient was $\mathrm{G}=0.6$. The ground absorption coefficients were determined in accordance with STN ISO 9613-2 Acoustics. Attenuation at sound propagation in outdoor areas. For better presentation of the development of noise situation of individual modeled variants - Figure 3, computational monitoring points (MPs) were implemented in the model for selected objects ( $2 \mathrm{~m}$ in front of the facade). These points are located at heights equal to the centre of the individual above-ground floors of the selected representative objects.

\section{In terms of noise, the following measures were simulated on the main road routes of the model:}

- change of road surface

- speed reduction from $50 \mathrm{~km} / \mathrm{h}$ to $30 \mathrm{~km} / \mathrm{h}$

- standard intersections were replaced by roundabouts

- noise barriers were built in exposed areas

- building a bypass along with the introduction of a residential zone

\section{CONSTRUCTION OF CIRCULAR INTERSECTIONS}

Circular intersections are constructed at the places where the zero option consisted of modeled standard intersections on the entrances to the built-up area. In terms of the transport organization, roundabouts are one of the popular solutions to traffic situations. Within the modelling in this particular area, the impact of noise after the realization of roundabouts on residential development in the computational area was investigated.

A speed of $50 \mathrm{~km} / \mathrm{h}$ has been defined in the model area except for speed reduction:

- $70 \mathrm{~m}$ before the roundabout to $40 \mathrm{~km} / \mathrm{h}$

- 50 before the roundabout to $30 \mathrm{~km} / \mathrm{h}$

- $30 \mathrm{~m}$ before the roundabout to $20 \mathrm{~km} / \mathrm{h}$; including the passage

This reduction increased speed, as a function of distance from a roundabout is intended to take into account acceleration or deceleration, which is a real phenomenon in normal traffic. The financial intensity of the whole measure is expected to be one of the more costly of the selected antinoise measures.

The average price of a roundabout with a diameter of 30 meters is around $€ 1,327,756$ including labour and landscaping. If we assume that the cost of labour, excavation and compaction will be half the total, then the cost of materials will be $€ 663,878$. The following table shows a simple financial calculation for the construction of three roundabouts with a diameter of $30 \mathrm{~m}$. The price calculation does not take into account the price of labour and the price of excavation and compaction works. 


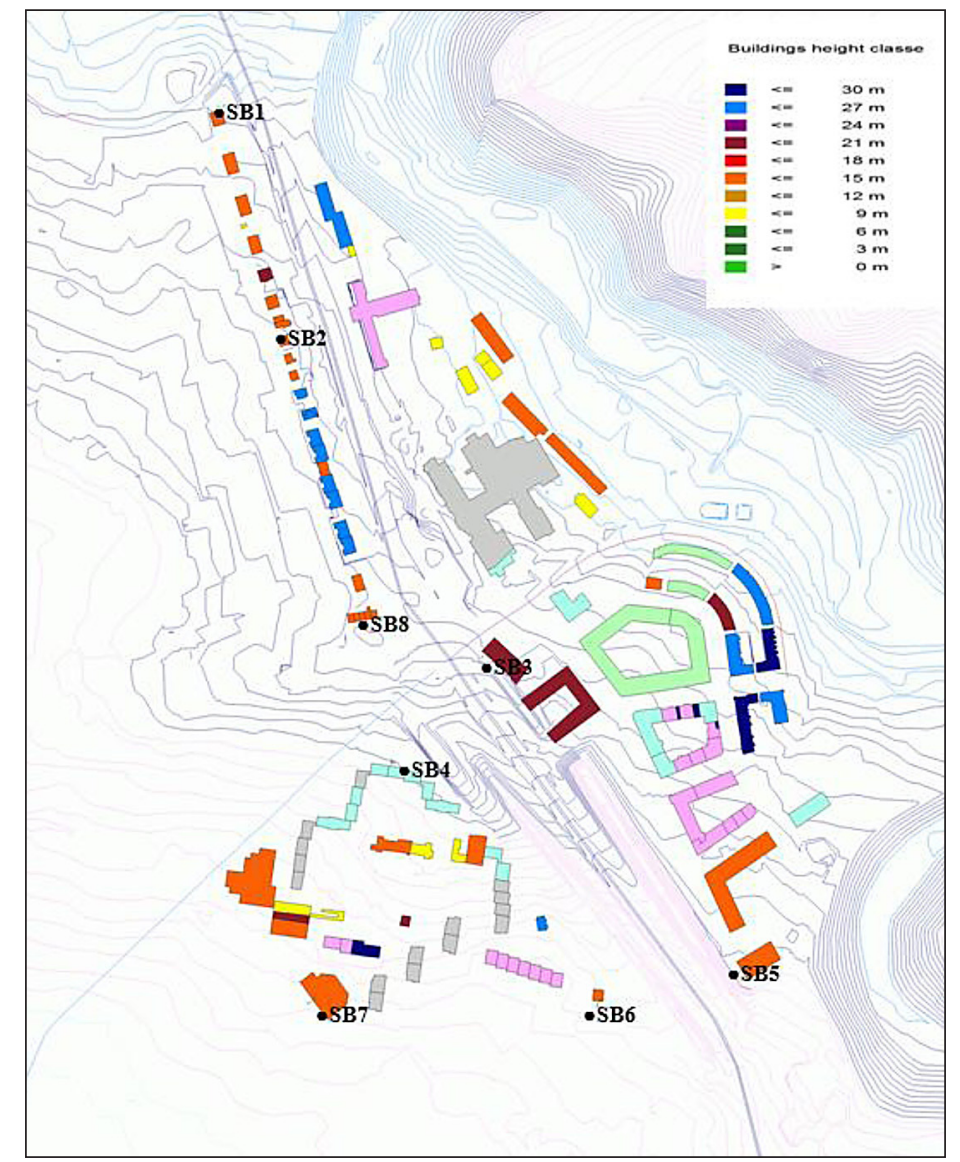

Fig. 3. Modeled area showing the calculated of monitored points (MP)

Table 1. The funds needed in the construction of circular intersections

\begin{tabular}{|c|c|c|c|}
\hline Name & Intersection diameter $[\mathrm{m}]$ & $\begin{array}{c}\text { Estimated price in } € \text { without VAT } \\
\text { for } 1 \text { intersection }\end{array}$ & $\begin{array}{c}\text { Price in } € \text { without VAT } \\
\text { for } 3 \text { intersections }\end{array}$ \\
\hline Circular intersection & 30 & 663878 & 1991634 \\
\hline
\end{tabular}

\section{The reference time interval - day}

The Table 2 shows the calculated values of equivalent sound pressure levels $\mathrm{A}$ at monitored calculation points for the variant with construction of roundabouts.

The visualization for the reference time interval - day is presented in the Figure 4 for the roundabout variant.

From the abovementioned information, it can be stated that after the realization of circular intersections at three places of the modelled area the noise situation does not improve within the reference time interval - day. The observed levels were found again in the observed calculation points MP 5, MP 6 and MP 7 in the 1st aboveground floor. It should be noted that at the observed calculation points MP 5 and MP 6 , the difference from the maximum permissible value is only 0.2 and $0.6 \mathrm{~dB}$, respectively. However, the above measure clearly causes the accumulation of noise at the points of entry and exit to and from roundabouts and thus increases the noise load at the monitored points located near the roundabouts. This measure does not produce any positive results in terms of noise reduction.

\section{The reference time interval - night}

The following input data were used for the calculation in the reference time interval - night; in the variant with the construction of three circular intersections on the main road of the model:

- standard bituminous road surface with a correction of $+1.1 \mathrm{~dB}$ for the deterioration of asphalt

- traffic intensity - passenger cars: 110 vehicles per hour, i.e. 880 passenger cars over the entire reference time interval 
Table 2. Calculated levels for a variant with the construction of roundabouts - reference time interval - day

\begin{tabular}{|c|c|c|c|c|}
\hline Observation point & Floor & $\mathrm{L}_{\text {Aeq, 16h }}[\mathrm{dB}]$ & Permitted value [dB] & Deviation from NPH [dB] \\
\hline \multirow{2}{*}{ MP 1} & 1.OGF & 72.4 & 60 & 12.4 \\
\hline & 2.OGF & 74.5 & 60 & 14.5 \\
\hline \multirow{3}{*}{ MP 2} & 1. OGF & 71.7 & 60 & 11.7 \\
\hline & 2. OGF & 72.2 & 60 & 12.2 \\
\hline & 3. OGF & 72,4 & 60 & 12.4 \\
\hline \multirow{4}{*}{ MP 3} & 1. OGF & 77.1 & 60 & 17,1 \\
\hline & 2. OGF & 78.5 & 60 & 18,5 \\
\hline & 3. OGF & 78.6 & 60 & 18,6 \\
\hline & 4. OGF & 77.2 & 60 & 17.2 \\
\hline \multirow{8}{*}{ MP 4} & 1. OGF & 67,4 & 60 & 7.4 \\
\hline & 2. OGF & 68.3 & 60 & 8.3 \\
\hline & 3. OGF & 68.5 & 60 & 8.5 \\
\hline & 4. OGF & 68.7 & 60 & 8.7 \\
\hline & 5. OGF & 68.7 & 60 & 8,7 \\
\hline & 6.OGF & 68,8 & 60 & 8,8 \\
\hline & 7. OGF & 68.8 & 60 & 8,8 \\
\hline & 8. OGF & 68.8 & 60 & 8.8 \\
\hline \multirow{3}{*}{ MP 5} & 1. OGF & 59.8 & 60 & -0.2 \\
\hline & 2. OGF & 67.5 & 60 & 7.5 \\
\hline & 3. OGF & 69.0 & 60 & 9.0 \\
\hline \multirow{2}{*}{ MP 6} & 1. OGF & 59,4 & 60 & -0.6 \\
\hline & 2. OGF & 61.2 & 60 & 1.2 \\
\hline MP 7 & 1. OGF & 47,1 & 60 & -12.9 \\
\hline \multirow{2}{*}{ MP 8} & 1. OGF & 71,2 & 60 & 11,2 \\
\hline & 2. OGF & 72.8 & 60 & 12,8 \\
\hline
\end{tabular}

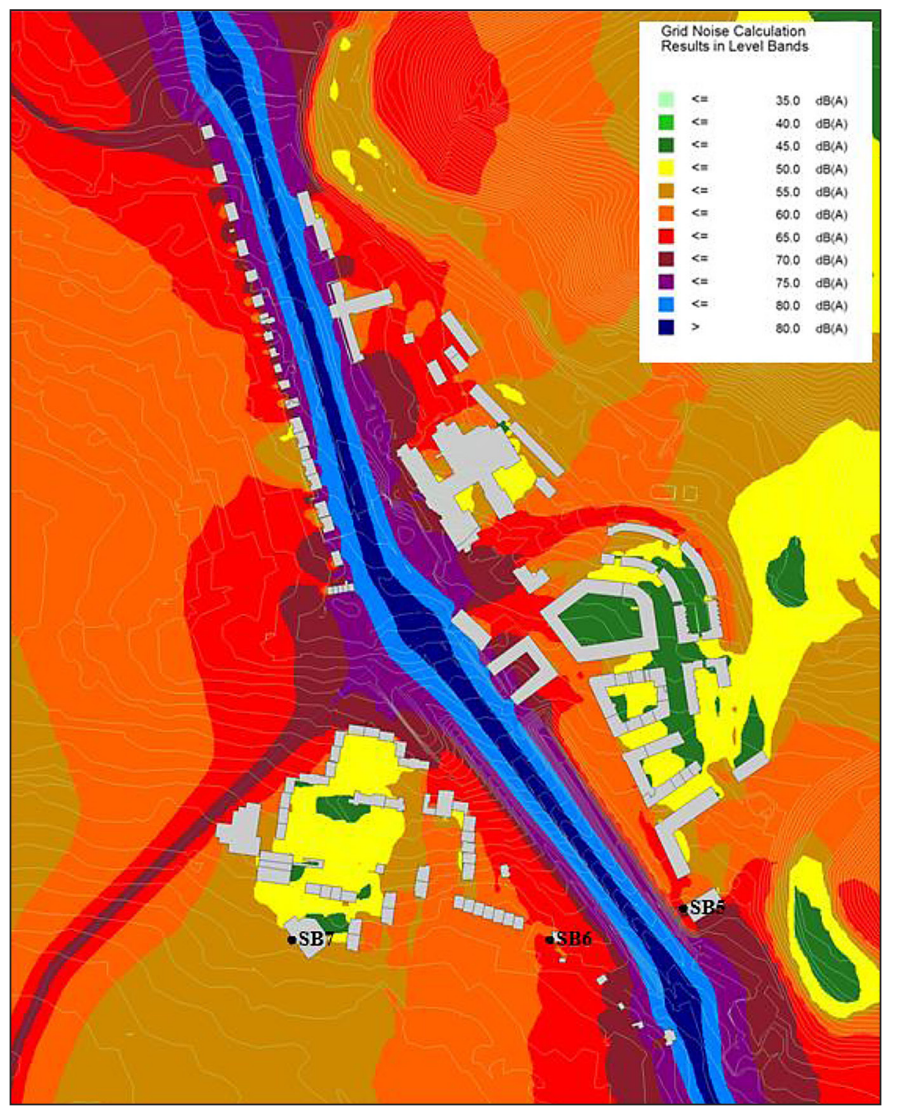

Fig. 4. Calculated levels for variant with construction of roundabouts - reference time interval - day 
Table 3. Calculated levels for a variant with the construction of roundabouts - reference time interval - night

\begin{tabular}{|c|c|c|c|c|}
\hline Observation point & Floor & $\mathrm{L}_{\mathrm{Aeq}, 8 \mathrm{~h}}[\mathrm{~dB}]$ & Permitted value [dB] & Deviation from NPH [dB] \\
\hline \multirow{2}{*}{ MP 1} & 1.OGF & 65.1 & 50 & 15,1 \\
\hline & 2.OGF & 66.7 & 50 & 16,7 \\
\hline \multirow{3}{*}{ MP 2} & 1. OGF & 64.1 & 50 & 14.1 \\
\hline & 2. OGF & 64.2 & 50 & 14.2 \\
\hline & 3. OGF & 64.5 & 50 & 14.5 \\
\hline \multirow{4}{*}{ MP 3} & 1. OGF & 69.6 & 50 & 19.6 \\
\hline & 2. OGF & 70.5 & 50 & 20.5 \\
\hline & 3. OGF & 70.5 & 50 & 20.5 \\
\hline & 4. OGF & 69.2 & 50 & 19.2 \\
\hline \multirow{8}{*}{ MP 4} & 1. OGF & 60.2 & 50 & 10.2 \\
\hline & 2. OGF & 60.5 & 50 & 10.5 \\
\hline & 3. OGF & 60,6 & 50 & 10.6 \\
\hline & 4. OGF & 60,7 & 50 & 10.7 \\
\hline & 5. OGF & 60.7 & 50 & 10.7 \\
\hline & 6.OGF & 60.7 & 50 & 10.7 \\
\hline & 7. OGF & 60.7 & 50 & 10.7 \\
\hline & 8. OGF & 60,8 & 50 & 10.8 \\
\hline \multirow{3}{*}{ MP 5} & 1. OGF & 53.0 & 50 & 3.0 \\
\hline & 2. OGF & 61.4 & 50 & 11.4 \\
\hline & 3. OGF & 61.5 & 50 & 11.5 \\
\hline \multirow{2}{*}{ MP 6} & 1. OGF & 53.2 & 50 & 3.2 \\
\hline & 2. OGF & 54.8 & 50 & 4.8 \\
\hline MP 7 & 1. OGF & 40.8 & 50 & -9.2 \\
\hline \multirow{2}{*}{ MP 8} & 1. OGF & 64.1 & 50 & 14.1 \\
\hline & 2. OGF & 65.0 & 50 & 15.0 \\
\hline
\end{tabular}

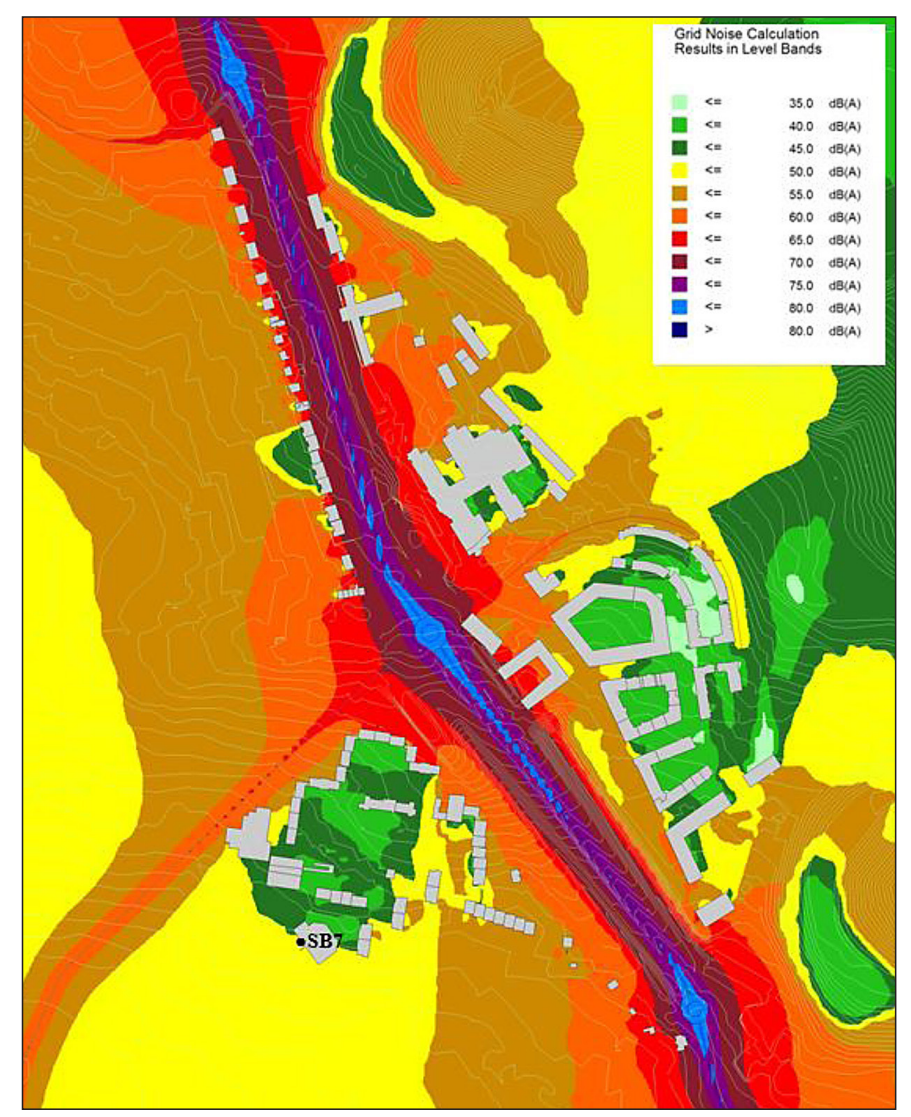

Fig. 5. Calculated levels for a variant with the construction of roundabouts - reference time interval - night 
- traffic intensity - trucks: 64 vehicles per hour, i.e. 512 trucks over the entire reference time interval

- vehicle speed: $50 \mathrm{~km} / \mathrm{h}$

- the proportion of cars and trucks remained the same as in the zero variant calculation

- taking account of acceleration and decellation before and after passing the roundabout

Figure 5 shows the equivalent sound pressure level A after the construction of roundabouts within the reference time interval - night at individual monitored calculation points, which are located on the facades of the selected objects.

On the basis of the visualization for the reference time interval - night for the variant with the construction of roundabouts, it is evident that noise, similarly to the visualization for the reference time interval - day, is accumulating near the roundabouts. The reason for this phenomenon is mainly the deceleration and subsequent acceleration of the vehicles, as the model was conceived taking into account the change of speed from $50 \mathrm{~km} / \mathrm{h}$ to $20 \mathrm{~km} / \mathrm{h}$ when passing the roundabout and vice versa.

Moreover, in this variant the noise situation worsened compared to "state zero", without any noise protection measures. The worsening reached area magnitude from 0.1 to $3.1 \mathrm{~dB}$ depending on the selected part of the calculation area. Again, the maximum permissible values were observed only in the case of the computed point MP 7, which was located on the most favourable place with respect to the model road.

\section{CONCLUSIONS}

The mathematical model of road traffic noise prediction was processed using the Lima prediction software, which has great potential and provides effective means for analyzing the traffic processes in the area of noise pollution. It can be said that the higher the proportion of urbanization in a given area, the greater the problem of noise remediation. The model described herein has a wide potential application and the document presented a simulation of one measure when used on the main road routes of the model, i.e. the construction of roundabouts.

However, the solution of a noise situation is always dependent on the specific situation and therefore this measure may be appropriate but not necessarily suitable for another type of territory. From the point of view of the traffic organization, roundabouts are popular solutions to traffic situations. The created simulation model has potential applications in traffic management, elimination or mitigation of traffic noise and in creating the noise maps of the territory. The model is designed to demonstrate the basics of using infrared technology applied in road traffic to mitigate the noise pollution that needs to be monitored, reduced or eliminated.

\section{Acknowledgements}

This work is a part of these projects VEGA 1/0063/16, KEGA 012TUKE-4/2019, KEGA 013TUKE-4/2019 and APVV SK-SRB-18-0053.

\section{REFERENCES}

1. Brenner T. Návrh a vizualizácia protihlukových opatrení v cestnej doprave. Diploma works in Slovak. Košice: TU FBERG, 2012, pp. 103.

2. Gozalo G.R., Escobar V.G., Morillas, J.M.B., Gonzalez, D.M. and Moraga P.A. Statistical attribution of errors in urbannoise modeling. Applied Acoustics 153, 2019, 20-29.

3. Xu YA., Zhu YM. and Qin ZK. Urban noise mapping with a crowd sensing system. Wireless networks 25, 2019, 2351-2364.

4. Paschalidou A.K., Kassomenos P., Chonianaki F. and Valkouma T. 3-year noise monitoring and strategic noise mapping in an extended motorway. Environmental science and pollution research 26, 2019, 15608-15616.

5. Bocher E., Guillaume G., Picaut J., Petit G. and Fortin N. Noise Modelling: Opensource GIS based tool to produce environmental noise maps. Isprs international journal of geo-information 8, 2019.

6. Ning X., Qi JY., Wu CL. and Wang WJ. Reducing noise pollution by planning construction site layout via a multi-objective optimization. Journal of cleaner production 222, 2019, 218-230.

7. Vasilyev A.V. Russian experience of transport noise estimation and mapping. Akustika 32, 2019, 105-109.

8. Alias F. and Alsina-Pages R.M. Review of wireless acoustics ensornet works for environmental noise monitoring smart cities. Journal of sensors 2019.

9. Benliay A., Ozyavuz M., Cabuk S. and Gunes M. Use of noise mapping techniques in urban landscape design. Journal of environmental protection and ecology 20, 2019, 113-122. 
10. Van Renterghem T. and Botteldooren D. Landscaping for road traffic noise abatement: Model validation. Environmental modelling \& software 109, 2018, 17-31.

11. Saran S., Oberai K., Wate P., Konde A., Dutta A., Kumar K. and Kumar A.S.Utilities of virtual 3D city models based on CityGml: various use cases. Journal of the indian society of remote sensing 46 , 2018, 957-972.

12. Dostupné na internete: < https://www.researchgate.net/figure/Figure-Comparison-of-levels-ofnoise_fig4_330561450> [Access: 2019-10-8]. 